\title{
Professor tutor: papéis, funções e desafios
}

\author{
Marta Fernandes Garcia \\ Instituto Federal de São Paulo \\ Universidade Estadual de Campinas
}

Dirceu da Silva

Universidade Estadual de Campinas

\section{Resumo}

O texto apresenta os resultados de uma investigação sobre o papel e a prática de professores tutores de diferentes regiões do país que trabalham com a formação de professores a distância. Um questionário foi aplicado a 386 professores tutores para avaliar os diferentes papéis que ocupam e a intensidade com que se percebem neles, bem como as funções desenvolvidas por esses sujeitos. Os dados foram submetidos a análises descritivas e cruzamentos. Os resultados evidenciam que o tutor carece de identidade profissional e que, apesar da variedade de papéis ocupados simultaneamente, exerce com maior intensidade o papel de motivador. Suas funções revelam transitoriedade entre uma prática pedagógica e uma prática administrativa.

Palavras-chave: Professor tutor. Formação de professores. Educação a distância 


\section{Teacher tutor: roles, functions and challenges}

\section{Abstract}

This paper shows the results of an investigation about the role and practice of tutoring teachers from different regions of Brazil that work with distance teachers training. A questionnaire was administered to 386 tutors to assess the different roles they play and the intensity with which they notice them as well as the functions developed by these subjects. The data were subjected to descriptive analysis and intersections. The results show that the tutor needs professional identity and, despite the variety of roles simultaneously played by tutors, the one they play more intensely is the motivating one. Their functions show transience from pedagogical practices concerning collaboration in the teaching and learning process and administrative practices of support.

Keywords: Teacher tutor .Teachers education. Distance Education.

\section{Profesor tutor: roles, funciones y retos}

\section{Resumen}

El artículo presenta los resultados de una investigación sobre el papel y la práctica de tutores de diferentes regiones de Brasil que trabajan con la formación del profesorado en la educación a distancia. Se aplicó un cuestionario a 386 profesores tutores con el objetivo de evaluar los diferentes roles que ocupan y la intensidad con la que se perciben en ellos, además de buscar observar las funciones realizadas por estos profesionales. Se realizó el cruce de todos los datos que fueron sometidos a análisis descriptivos. Los resultados muestran que el profesor tutor carece de identidad profesional y que, a pesar de la variedad de papeles que ocupan a la vez, lo que ejecuta con mayor intensidad es el papel de motivador. Sus funciones revelan una transitoriedad entre una práctica pedagógica, de colaboración con el proceso de enseñanza y aprendizaje, y una práctica administrativa, de apoyo.

Palabras clave: Profesor tutor. Formación de profesores. Educación a distancia. 


\section{Enseignant tuteur: rôles, fonctions et défis}

\section{Résumé}

Cet article montre les résultats d'une enquête sur le rôle et la fonction des enseignants tuteurs dans différentes régions du Brésil qui travaillent pourla formation des enseignants a distance. Un questionnaire a été administré à 386 tuteurs pour évaluer les différents rôles qu'ils jouent et l'intensité avec laquelle ils les notent ainsi que les fonctions développées par leur sujets. Les données ont été soumises à une analyse descriptive et comparative. Les résultats montrent que le tuteur a besoin d'un titre \& cadre professionnel et, malgré les differents rôles qu'ils jouent déja , car celui du tutorat est plus motivant. Leurs fonctions montrent une grande différence avec les pratiques pédagogiques usitées concernant l'enseignement et d'apprentissage de soutien.

Mots-clés: Enseignant tuteur. L'enseignement à distance

\section{Introdução}

As propostas de formação a distância proliferam-se de forma rápida no cenário educacional brasileiro, sobretudo no campo da educação. Dados do INEP (2016) evidenciam que é na área de formação de professores, em especial, na pedagogia, que está o maior número de matrículas nos cursos a distância. Sabemos que os avanços da tecnologia da informação e comunicação (TIC) têm possibilitado o oferecimento de diferentes programas para a formação de professores a partir do uso de tecnologias no processo de ensino-aprendizagem. Desta forma, instaura-se um amplo campo de desenvolvimento de estratégias e políticas dirigidas à educação a distância.

No Brasil, país com grandes dimensões, profundas desigualdades sociais e econômicas e uma história da educação marcada pela exclusão, a educação, em seus aspectos de acesso, permanência e qualidade, sempre se constituiu em grande desafio em todos os níveis de ensino. Com os avanços tecnológicos ao longo dos anos, em especial, após o surgimento da internet, esse desafio, ainda que aparente o contrário, tomou uma dimensão ainda maior, uma vez que formar sujeitos com uso de tecnologias digitais é tarefa complexa, que exige conhecimentos específicos, além dos tradicionalmente necessários para exercer a docência. As tecnologias tornam a prática pedagógica mais complexa, pois "as TIC na educação são elementos dificultadores que exigem pensar a educação muito além de um campo fechado em si mesmo" (Lapa; Pretto, 2010, p. 
94). Esse desafio é ampliado quando constatamos que estas mesmas tecnologias não estão ao alcance de todos e nem são apropriadas por docentes e alunos da mesma forma e com a mesma intensidade. Assim, temos em nosso cenário um expressivo e desigual avanço tecnológico (Tezanos, 2011; Dourado, 2008).

Com a inauguração de ambientes virtuais de aprendizagem, a EaD tem sido considerada, muitas vezes, a solução para os problemas de formação inicial e continuada, assim como para promover justiça social e democratização do acesso à educação (Ferreira; Garrido, 2005; Pradro; Almeida. 2003). Desta forma, tem sido a modalidade estrategicamente utilizada pelo Estado para atender a demanda reprimida por formação em nível superior (Freitas, 2007), objetivo que tem lugar de destaque na Lei de Diretrizes e Bases da Educação Nacional (Lei n 9.394/96). Inclusive, o Plano Nacional de Educação (PNE) 2014-2024 apresenta em suas estratégias o uso da EaD para atingir metas de ampliação da oferta de vagas no ensino superior e também de cursos de pós-graduação stricto sensu, especialmente por meio da Universidade Aberta do Brasil. No entanto, Dourado (2008) esclarece que a EaD é considerada por alguns como a resolução dos problemas de formação e para outros um modo aligeirado de formar professores. Entretanto, considera fundamental romper com posições extremistas e atentar para questões centrais: projeto pedagógico, condições objetivas, concepção de aprendizagem, dentre outros.

É necessário atentar, ainda, para as fortes críticas dirigidas a esta modalidade. Freitas (2007), Dourado (2008) e Garcia (2009) argumentam que o crescimento notável de cursos a distância se dá, principalmente, na área da educação e na esfera privada e não conta com a devida infraestrutura, planejamento e pessoal qualificado, o que põe em risco investimentos e a possibilidade de boa formação. É com esta preocupação que Freitas (2007) afirma que a maioria dos cursos de formação pela EaD tem se apresentado como uma forma de aligeirar e baratear o processo formativo, mas a oferta de cursos por instituições públicas de ensino superior representa uma ruptura com programas de formação com viés mercadológico.

Posto isto, um dos principais desafios a ser enfrentado na educação a distância se refere à precarização do trabalho docente presente, muitas vezes, nesse modelo. Com uma carga horária de trabalho exaustiva, baixa remuneração e pouco reconhecimento profissional, o professor tutor é contratado em regime precário para desempenhar, muitas vezes, o papel de professor (Lapa; Pretto, 2010). A atuação e formação deste profissional requer atenção e investimentos, uma vez que este emergente ator tem exercido papel fundamental na formação de professores a distância (Garcia; Silva, 2013). Neste sentido, o presente artigo tem por objetivo discutir o complexo papel e funções delegadas ao professor tutor e, ao mesmo tempo, refletir sobre suas representações e práticas. 


\section{Sobre a complexidade do papel e função do professor tutor: em busca de identidade}

A educação a distância cresce consideravelmente desde 2001 (INEP 2016), e, com ela, uma recente figura ganha relevo neste cenário: o professor tutor. Assim, perguntas fundamentais surgem: o que significa ser um professor tutor ${ }^{1}$ ? De onde e quando surgiu esse termo? Dentro de uma acepção semântica, tutor significa "indivíduo que exerce uma tutela, aquele que ampara, protege, defende, guardião" (Houaiss Dicionário Eletrônico, 2007). "Indivíduo legalmente encarregado de tutelar alguém, protetor" (Ferreira, 2010). Historicamente, a figura do tutor nasce no século $\mathrm{XV}$, nas universidades inglesas de Oxford e Cambridge, com a função de assessorar grupos de alunos em seus estudos. No século XIX, a função de tutor passa a ser institucionalizada nas universidades e a fazer parte da composição do quadro docente (Preti, 2003). Ainda para o autor, esse modelo tutorial presencial influenciou muito a configuração da tutoria implementada pela primeira universidade a distância, a Open University, em 1969, e outras que surgiram na sequência.

Nas perspectivas tradicionais de $\mathrm{EaD}$, o tutor era considerado um guia, "que dirigia, orientava, apoiava a aprendizagem dos alunos, mas não ensinava" (Maggio, 2001, p.95). A crença era de que o material realizava a tarefa de ensinar e que ao tutor estava reservada apenas a função de acompanhar o processo e assegurar o cumprimento dos objetivos. Na década de 80 , inicia-se, no campo educacional, um processo de mudança de concepção pedagógica e a ênfase deixa de ser a transmissão de informação e passa a ser a construção de conhecimentos, o que trouxe à escola e ao professor novos desafios no desenvolvimento de planejamentos que desencadeassem processos de reflexão e questionamento, ao invés de memorização de conteúdos. Já nas perspectivas pedagógicas atuais, o trabalho do tutor ganha uma nova dimensão devido à compreensão e ao aprofundamento das formas como se aprende e se ensina. Assim, um bom tutor, dentro dessa perspectiva, é aquele que promove tarefas desafiadoras e acompanha sua resolução, fornece fontes de informação, favorece a compreensão e oferece explicações substantivas (Maggio, 2001).

Importante observar que há maior consenso na literatura sobre as funções do professor tutor do que em relação ao seu papel, ainda que as funções variem de acordo com as concepções presentes em cada instituição ou programa de formação. Belloni (2009) afirma que uma das questões centrais na análise da EaD e, talvez, a mais polêmica, refere-se ao papel do tutor nesta modalidade. Para a autora, ele é convocado a assumir múltiplas funções, para muitas das quais não se sente e, de fato, não foi preparado para assumir. Para Leal (2004, p. 4) ser tutor significa ser

1 Diferentes nomenclaturas são utilizadas para fazer referência ao tutor. Preferimos o termo professor tutor por acreditarmos que este profissional também desenvolve uma função pedagógica que colabora para a aprendizagem do aluno. Esclarecemos que, por vezes, será utilizado o termo tutor para se reportar ao modo como entidades e/ ou autores utilizam. 
um "professor/andragogo com competência para organizar pesquisas criativas e situações provocativas". Para a autora, o tutor é um profissional que deve possuir sólida formação acadêmica, com conhecimentos didático-pedagógicos para relatar experiências, orientar leituras e pesquisas, compartilhar estratégias de aprendizagem e orientar debates em fóruns de discussão.

A complexidade do papel do professor tutor (ser ou não professor) e o fato de encontrarmos diferentes nomenclaturas para esta função na literatura, exige pensarmos quem é este sujeito e a prática que ele desenvolve. A identidade construída por este profissional é aspecto relevante, pois repercute nas ações que por ele serão desenvolvidas em seu trabalho com os alunos. Se por um lado, o professor tutor entende que seu ofício está voltado para questões administrativas e técnicas, pouca preocupação terá com as questões pedagógicas. Mas, se por outro lado ele compreende que sua tarefa é uma atividade educativa, com dimensão social, suas ações contribuirão significativamente para a formação do futuro professor e estarão voltadas para o pedagógico:

Uma identidade profissional se constrói, pois, com base na significação social da profissão; na revisão constante dos significados sociais da profissão; na revisão das tradições. [...] Constrói-se, também, pelo significado que cada professor, enquanto ator e autor, confere à atividade docente no seu cotidiano, com base em seus valores, em seu modo de situarse no mundo, em sua história de vida, em suas representações, em seus saberes, em suas angústias e anseios, no sentido que tem em sua vida o ser professor. [...] Nos processos de construção da identidade docente, tem papel fundamental o significado pessoal que os professores atribuem a si mesmos e à educação escolar. (Pimenta; Anastasiou, 2010, p. 77)

Encontramos, na literatura da área, diferentes denominações atribuídas ao profissional genericamente intitulado tutor: instrutor, facilitador, guia, monitor, orientador, motivador, formador, moderador, conselheiro, entre outras. Cada termo explicita uma concepção sobre o significado de ser tutor e, consequentemente, sobre o trabalho que se espera por ele ser desenvolvido. Esse grande número de terminologias desencadeia confusas concepções e representações por parte do profissional tutor que não consegue, muitas vezes, definir claramente o seu papel. Isso se deve, em grande parte, aos diferentes programas e instituições que apresentam, cada qual, a sua concepção particular de tutoria. A complexidade reside no fato de que identidades múltiplas atribuídas a um mesmo indivíduo pode significar "fonte de tensão e contradição tanto na auto-representação quanto na ação social" (Castells, 2002, p. 22).

Diante de confusas representações, o grande risco ao trabalho do professor tutor é a perda da essência do ser docente, em outras palavras, a perda do lugar de profissional da educação para estar voltado a ações pouco ou nada pedagógicas (Maggio, 2001). Se o controle por parte do sistema for excessivo, com atividades totalmente estruturadas preconcebidas, com alta valorização do material didático, 
corre-se o risco do professor tutor perder flexibilidade e autonomia para realizar intervenções qualitativas, o que significaria um retrocesso epistemológico na forma de conduzir um processo formativo a distância.

Muitos são os autores que discutem o papel do tutor, assim como a melhor nomenclatura. Lapa e Pretto (2010) argumentam que o tutor é um professor na medida em que desempenha esse papel no ambiente virtual. Moore e Kearsley (2008) afirmam que se trata de um instrutor que está ligado a funções de ensino, acompanhamento e apoio ao aluno. Palloff e Pratt (2002) apontam que o seu papel é o de um facilitador. Alonso e Alegretti (2003) sinalizam que se trata de um professor que assume a posição de formador, orientador e provocador para potencializar a aprendizagem dos alunos. Emerenciano et al. (2001) também evidenciam que trabalhar como tutor significa ser professor e educador. Por sua vez, Silva et al. (2009) defendem que o papel do tutor é mais importante do que o papel de facilitador ou de transmissor, pois seu trabalho se dá em um contexto dinâmico e complexo, que exige criatividade.

Almeida (2003) e Maggio (2001) aproximam-se em suas definições. A primeira denomina o tutor como docente formador, que tem ao mesmo tempo os papéis de mediador, moderador, observador e articulador, cuja principal função é orientar a aprendizagem do aluno. Na mesma direção, a segunda autora afirma ser professor tutor a melhor nomenclatura, devido à função de docente que exerce esse sujeito em ambiente virtual, uma vez que o que se espera é que ele acompanhe o processo de aprendizagem e oriente os alunos. Acreditamos ser esta a melhor nomenclatura, pois esse profissional assume uma tarefa educativa e pode colaborar decisivamente para a formação professores. Esta posição também é defendida por Belloni (2009), para quem o tutor possui, inegavelmente, uma função pedagógica na medida em que tem que dar conta da difícil tarefa de levar o aluno a aprender. Ainda que não seja dele a responsabilidade de produzir materiais didáticos, é do professor tutor que se espera, na maioria das vezes, a realização da tarefa de mediação.

É recorrente na literatura e em documentos oficias que uma das principais funções do tutor é realizar a mediação. Pimenta e Anastasiou (2010) discutem a mediação reflexiva e defendem que se trata de uma tarefa complexa, de um trabalho de investigação que consiste em levar o aluno à atividade ativa de construir conhecimentos significativos. Neste mesmo sentido, Mauri e Onrubia (2010) esclarecem que a atividade tutorial é concebida como mediação da atividade do aluno. Masetto (2009) aponta importantes características da mediação pedagógica, dentre elas: o diálogo permanente; a troca de experiências; a cooperação para que o aluno domine as novas tecnologias em suas aprendizagens; a proposição de situações-problema, perguntas orientadoras e desafios. O autor descreve a mediação como o comportamento do professor de incentivador e motivador da aprendizagem, com a disposição de ser ponte entre o aluno e o conhecimento (Masetto, 2009). Importante ressaltar que a mediação pedagógica não se dá somente entre professor e aluno. Trata-se também de criar 
situações que aproximem os alunos entre si, fazendo com que assumam o papel de mediadores dos colegas e desenvolvam compromisso e autonomia (Prado; Almeida, 2003).

O Quadro 1 apresenta os diferentes papéis do professor tutor encontrados na literatura. A lista poderia ainda ser maior. Contudo, os papéis elencados abaixo se tornaram recorrentes e a intenção é mostrar os principais papéis que estes profissionais geralmente assumem na EaD.

Quadro 1- Papéis do tutor identificados na literatura

\begin{tabular}{|l|l|}
\hline Papel do tutor & Referências \\
\hline $\begin{array}{l}\text { Parceiro do estudante no processo de } \\
\text { conhecer }\end{array}$ & Lapa e Pretto (2010) \\
\hline Professor & Belloni (2009) \\
\hline Instrutor & Moore e Kearsley (2008) \\
\hline Orientador/ Guia/ Formador/ Dinamizador & Berrocoso e Garrido Arroyo (2005) \\
\hline Facilitador & Palloff e Pratt (2004) \\
\hline Educador/ Professor/ Andragogo & Leal (2004) \\
\hline Formado/ Orientador/ Provocador & Alonso e Alegretti (2003) \\
\hline Motivador/ Orientador/ Animador & García Aretio (2003) \\
\hline Docente-formador & Almeida (2003) \\
\hline Professor e educador & Emerenciano et al. (2001) \\
\hline Professor-tutor & Maggio (2001) \\
\hline $\begin{array}{l}\text { Administrador/ Facilitador/ Bombeiro/ } \\
\text { Suporte/ Negociante/ Filtro/ Líder da } \\
\text { discussão/ Especialista/ Editor }\end{array}$ & Berge e Collins (2000) \\
\hline
\end{tabular}

Fonte: elaborado pelos autores.

Em que pese a discussão sobre o seu papel, é consenso na literatura que a atuação do professor tutor é relevante para o sucesso da formação de professores e para a baixa taxa de evasão. Encontramos esta argumentação em Gatii (2003), Preti (2003), Palloff e Pratt (2004), Berrocoso e Garrido Arroyo (2005), Chaney et al. (2007), Moore e Kearsley (2008), Prado e Almeida (2003) e Garcia e Silva (2013). É o professor 
tutor que, na maioria das vezes, dialoga com os alunos, orienta leituras e auxilia na superação de dúvidas. Ele é a figura-chave no processo motivacional e afetivo (Gatti, 2003).

Para Moulin et al. (2004), o tutor deve orientar a elaboração do plano de estudos, acompanhar a aprendizagem, e, à luz dos resultados da avaliação, intervir. Para as autoras, a função do tutor está dividida em três vertentes: (1) Função de Aconselhamento: preocupação com a motivação e incentivo constante ao aluno durante todo o curso; formação de valores, hábitos e atitudes, em especial, voltadas à autoafirmação e à valorização do bem estar da humanidade. (2) Função de Orientação da Aprendizagem - voltada para a formação do saber (conhecimentos) e do "saberfazer" (habilidades e capacidades específicas). Inclui indicar fontes de informação e propor atividades criativas e desafiadoras. (3) Função de Avaliação - relevante para o sucesso da aprendizagem, pois pode interferir positiva ou negativamente na formação do aluno. Para Gaytan e McEwen (2007), os professores tutores precisam avaliar as tarefas dos alunos não como uma prestação de contas, mas como uma forma de contribuir para a sua aprendizagem.

Para Silva et al. (2009), o professor tutor deve conhecer o projeto político pedagógico do curso e o conteúdo das disciplinas. Argumentam que o trabalho deste profissional envolve quatro dimensões: conhecimento, aprendizagem, motivação/presença e disponibilidade. Estimular as relações humanas, construir um ambiente favorável para a aprendizagem, orientar o aluno e oferecer feedback são tarefas importantes do professor tutor. A motivação e o feedback exigem ser analisados com maior cuidado.

Gaytan e McEwen (2007) apontam que o feedback é fundamental e deve ser apropriado e significativo. Para os autores, o professor tutor precisa interagir com os alunos e utilizar diferentes estratégias e ferramentas, fornecendo um feedback detalhado e imediato. Na mesma direção, Chaney et al. (2007) sinalizam que um dos indicadores de qualidade da EaD é o rápido feedback fornecido pelo tutor. Palloff e Pratt (2004) consideram que o feedback deve conter uma mensagem substancial, clara, precisa, que responda às questões levantadas pelos alunos, que apresente reflexões e que contribua para o aprofundamento do tema. Para Maggio (2001), o feedback significa fazer intervenções coerentes e aproveitar as oportunidades para aprofundar o debate, evitando uma construção errônea por parte do aluno. Moore e Kearsley (2008) também apontam a relevância dos alunos receberem feedback sobre as tarefas com informações a respeito dos seus progressos, pontes fortes e fracos e ressaltam a importância da percepção que deve possuir o professor tutor em relação ao envio de feedback individual ou para toda a turma. No entanto, Palloff e Pratt (2004) pondera que intervir em demasia nos fóruns pode ser prejudicial ao bom andamento das discussões e que é preciso saber equilibrar a quantidade e a frequência de feedbacks.

A motivação está intrinsecamente relacionada com o feedback. Os alunos, ao receberem mensagens do professor tutor, sentem sua presença e afastam o sentimento de abandono e o desejo de desistir do curso. Por esta razão, Palloff 
e Pratt (2002) entendem que uma das funções do professor tutor é atuar como um motivador de seus alunos, incentivando-os a se conhecerem, a construírem um ambiente agradável, uma comunidade virtual ${ }^{2}$ e a explorarem o material didático profundamente. Na mesma direção, Moulin et al. (2004) defendem a necessidade de motivar o aluno ao longo de sua trajetória. Para tanto, é preciso conhecer o perfil do aluno, seus interesses e dificuldades. E, para superar o mito do isolamento nos cursos online, é importante o professor tutor incentivar o diálogo entre os alunos, estimular a autoconfiança, a iniciativa e a tomada de decisões. Sobre este aspecto, é pertinente observar o que aponta Gatti (2003), quando da importância de se construir uma relação afetiva com os alunos:

Os conhecimentos adquirem sentido ou não, são aceitos ou não, incorporados ou não, em função de complexos processos não apenas cognitivos, mas, socioafetivo e culturais. Essa é uma das razões pelas quais tantos programas que visam a mudanças cognitivas, de práticas, de posturas, mostram-se ineficazes. Sua centralização apenas nos aspectos cognitivos individuais esbarra nas representações sociais e na cultura de grupos (Gatti, 2003, p.2).

Muitas são as tarefas postas ao professor tutor. O Quadro 2, criado a partir da revisão da literatura da área, reúne as diferentes categorias que envolve o seu trabalho.

Quadro 2- Funções do professor tutor

1- Colaboração no processo de ensino e aprendizagem - funções que têm natureza pedagógica, relacionadas diretamente com a prática educativa.

2- Motivação e humanização - funções relacionadas com a motivação e a disponibilidade ao aluno, com o estado de ânimo durante o processo de aprendizagem e com a humanização no ambiente virtual de aprendizagem.

3- Avaliação - funções relacionadas com o processo avaliativo, tanto da aprendizagem dos alunos quanto do curso e das ações desenvolvidas.

4- Gestão/Administração - funções relacionadas com questões de gerenciamento do ambiente virtual e de conhecimento/ envolvimento com conteúdos.

5- Crescimento Profissional - ações que demonstram preocupação do professor tutor com o seu cresciWmento profissional.

6- Técnica - Funções relacionadas com o uso de ferramentas tecnológicas e com a busca de soluções para problemas técnicos.

Fonte: elaborado pelos autores.

2 Lévy (2005, p. 27) define comunidade virtual como "um grupo de pessoas se correspondendo mutuamente por meio de computadores interconectados". 
que consideramos essencial ao se pensar a tarefa do professor tutor é a sua íntima relação com a aprendizagem do aluno. Para tanto, é preciso compreender o contradiscurso técnico, que insere o trabalho deste profissional não apenas no âmbito tecnológico, mas, decididamente, no campo educacional (Leal, 2004). A mudança de modalidade e, portanto, de ambiente, não altera a finalidade do ato educativo que é gerar aprendizagens. Deste modo, é evidente que profissionais voltados à formação de professores na EaD precisam ter conhecimentos sólidos sobre o trabalho de mediação pedagógica, o processo de construção de conhecimento em ambiente virtual, sobre as TIC, bem como as dimensões que envolvem a relação pedagógica, tanto do ponto de vista dos alunos quanto do professor e do trabalho pedagógico. Este último aspecto implica, de acordo com Cordeiro (2011), atentar para cinco dimensões dessa relação que podem interferir na aprendizagem dos alunos: cognitiva, espacial, temporal, linguística e pessoal. Certamente, a relação pedagógica ocupa espaço importante no processo de formação de professores e precisa ser examinada por aqueles que se dedicam a exercer a docência, seja ela em ambiente presencial ou virtual.

\section{Caracterização da pesquisa e perfil dos participantes}

Um questionário estruturado sobre as funções e papéis do professor tutor foi aplicado em 386 tutores que atuam em cursos superiores de formação de professores a distância em diferentes regiões do país. Os dados obtidos foram submetidos a cruzamentos e à análise descritiva, utilizando-se para esta finalidade o software Statistical Package for Social Sciences (SPSS) versão 15.0.

A análise do perfil dos sujeitos mostra que a maior parte é do sexo feminino $(67,6 \%)$, casado (58\%), formado em instituição pública superior (52,3\%) e possui outro emprego (87\%) e, destes, apenas 19,2\% consideram o emprego de tutor o principal. Ainda, $56,7 \%$ trabalha em instituições públicas de ensino superior. A faixa etária pode ser observada a seguir: 
Tabela 1- Faixa etária dos professores tutores

\begin{tabular}{|l|l|}
\hline Faixa etária & Valor absoluto \\
\hline 20 a 30 anos & 55 \\
\hline 31 a 40 anos & 123 \\
\hline 41 a 50 anos & 118 \\
\hline 51 a 60 anos & 68 \\
\hline Maior que 60 anos & 22 \\
\hline Total & 386 \\
\hline
\end{tabular}

Fonte: Dados da pesquisa. Elaboração dos autores.

A maioria dos sujeitos é formada em pedagogia (39,1\%), seguido de letras $(20,1 \%)$, biologia (4,7\%) e sociologia (3,4\%). Trabalha em instituições localizadas no Estado de São Paulo (51,8\%), Rio de Janeiro (15\%) e Distrito Federal (6,5\%). Os cursos em que atuam estão descritos na tabela 2 e o grau de escolaridade na tabela 3.

Tabela 2 - Cursos em que atuam como professor tutor

\begin{tabular}{|l|l|}
\hline Curso & Valor absoluto \\
\hline pedagogia & 171 \\
\hline letras & 37 \\
\hline artes visuais & 6 \\
\hline história & 3 \\
\hline biologia & 11 \\
\hline geografia & 2 \\
\hline física & 3 \\
\hline outros & 153 \\
\hline Total & 386 \\
\hline
\end{tabular}

Fonte: Dados da pesquisa. Elaboração dos autores. 
Tabela 3 - Nível de escolaridade

\begin{tabular}{|l|c|}
\hline Nivel & Valor absoluto \\
\hline *graduação & 23 \\
\hline especialização & 196 \\
\hline mestrado & 141 \\
\hline doutorado & 26 \\
\hline Total & 386 \\
\hline
\end{tabular}

Fonte: Dados da pesquisa. Elaboração dos autores.

O nível de escolaridade se torna preocupante quando levamos em consideração o disposto no art. 66 da LDB que garante: "a preparação para o exercício do magistério superior far-se-á em nível de pós-graduação, prioritariamente em programas de mestrado e doutorado". (Brasil, 1996, p. 23). Verificamos desconsideração à LDB, já que existem professores tutores atuando em curso superior tendo apenas a graduação e $56,73 \%$ não possuem mestrado ou doutorado.

\section{Os diferentes papéis do professor tutor}

Esta parte discute os dados referentes aos papéis ocupados por professores tutores no processo formativo de professores a distância. Aos respondentes, foi oferecido um quadro (figura 1) que apresentava diferentes papéis com uma breve descrição sobre cada um deles e solicitado que manifestassem a intensidade com que se viam neles. 
Figura 1 - Papéis do professor tutor - quadro disponibilizado aos respondentes

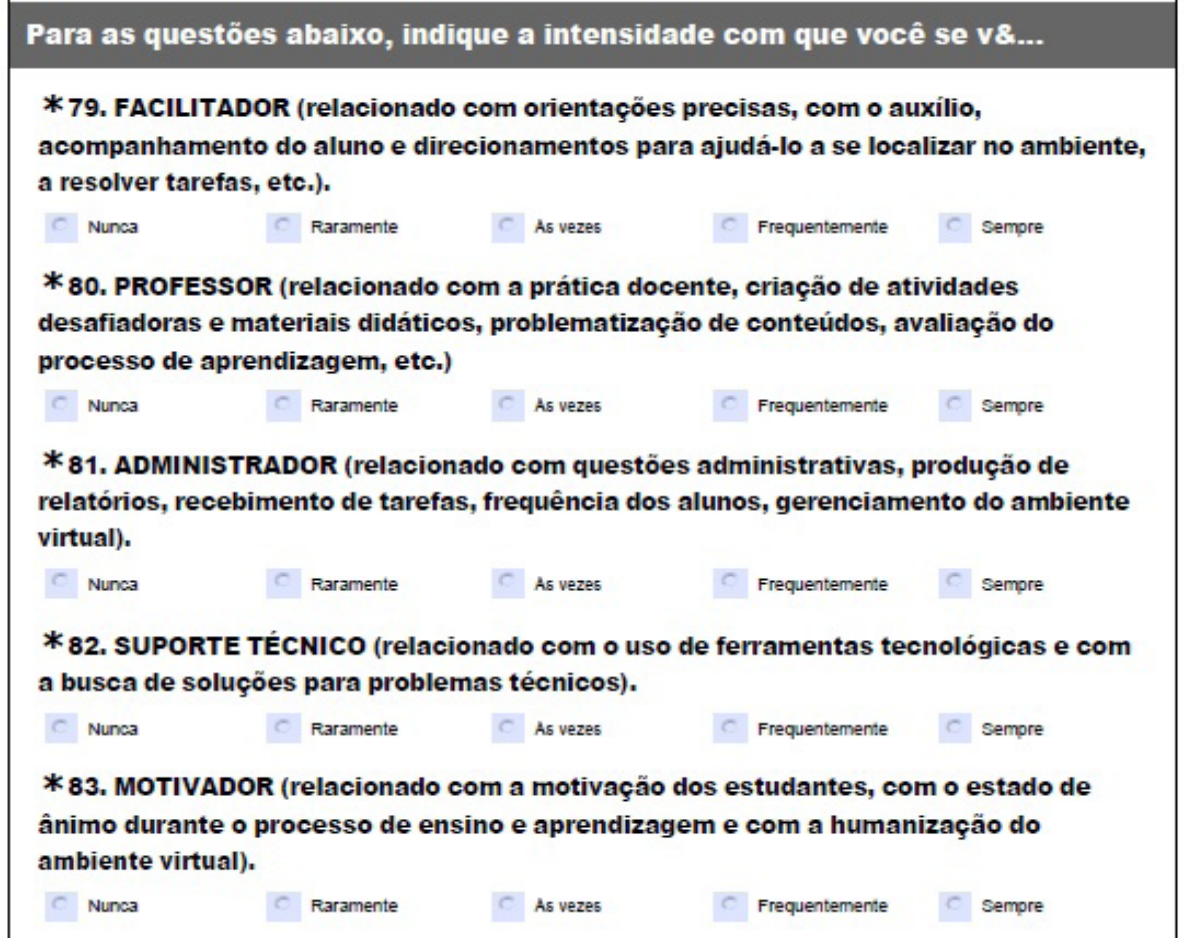

Fonte: Elaborado pelos autores.

A análise das respostas dos sujeitos revelou que a maioria se percebe, principalmente, no papel de motivador, pois $62,17 \%$ afirmaram que sempre se vê neste papel, cuidando da motivação dos estudantes ao longo de todo o curso e da humanização do ambiente virtual. Em segundo lugar, surge como mais frequente o papel de facilitador, uma vez que 55,95\% apontaram que sempre desenvolvem funções relacionadas com orientações precisas, com o auxílio, acompanhamento do aluno e direcionamentos para ajudá-lo a se localizar no ambiente e a resolver tarefas.

O papel de professor surge apenas em terceiro lugar. Do total de participantes (386), $38,86 \%$ afirmaram sempre se perceber neste papel, o qual está relacionado com a prática docente, com criação de atividades desafiadoras e materiais didáticos, com a problematização de conteúdos e com a avaliação do processo de aprendizagem.

Em quarto lugar, aparece o papel de administrador, em que 28,23\% relataram sempre ocupar este papel, cuidando de questões administrativas, da produção de relatórios, de recebimento de tarefas, da frequência dos alunos e do gerenciamento do ambiente virtual. 
Em quinto lugar, está o papel em que menos os sujeitos se percebem: suporte técnico. Apenas 15,80\% afirmam sempre ocupar este papel, colaborando com o uso de ferramentas tecnológicas e com a busca de soluções para problemas técnicos.

Essa variedade de papéis ocupados pelos sujeitos corrobora o que aponta Belloni (2009), quando afirma que uma das questões centrais e, talvez, a mais polêmica na EaD seja o papel assumido pelo professor na EaD. Os professores tutores participantes desta pesquisa, de fato ocupam, ao mesmo tempo, diferentes papéis. Mas, ser o motivador o papel que eles se vêem com maior intensidade indica que a grande preocupação desses sujeitos está em estimular as relações humanas e o bom estado de ânimo dos alunos ao longo do curso. Isto pode ocorrer pela pressão das instituições para conseguir manter um grande número de alunos e também pela compreensão dos próprios sujeitos de que é necessário criar um ambiente agradável e acolhedor para que os alunos sintam-se entusiasmados em aprender. Sabemos que na modalidade a distância o número de desistentes é grande (INEP, 2016) e motivar o aluno ao longo de todo o curso é altamente necessário para a permanência, engajamento e desenvolvimento do estudante.

O cruzamento entre escolaridade e papel nos permitiu perceber que os sujeitos que se percebem com maior intensidade no papel de motivador são aqueles que possuem, como grau máximo, a graduação e a especialização. No entanto, é interessante observar que os sujeitos que possuem doutorado também evidenciaram o papel de motivador como o mais frequente e, em seguida, o de professor ao lado do de facilitador. Somente os que possuem como grau máximo o mestrado escolheram o papel de facilitador em primeiro lugar ficando, com pouca diferença estatística, o de motivador em segundo. Estas constatações evidenciam que, de maneira geral, para os professores tutores participantes desta pesquisa, o papel de motivador surge como mais forte que o de professor no desenvolvimento de suas práticas.

Para Gatti (2003), o tutor possui a importante tarefa de motivar os alunos e de colaborar na construção de laços de afetividade. Um ambiente acolhedor e uma equipe atenciosa e disponível, certamente, colaboram para o entusiasmo dos alunos. Contudo, não podemos nos esquecer de que o rápido e significativo feedback é essencial para manter o aluno no curso e colaborar qualitativamente com sua formação. Quando suas dúvidas e anseios não são satisfatoriamente esclarecidos e quando a resposta é morosa, cresce largamente a possibilidade de desânimo e/ou abandono do curso. Decorremos disso que o papel de motivação sozinho não consegue dar conta da difícil tarefa de motivar o aluno e de mantê-lo comprometido com o curso e com a sua aprendizagem. É preciso que o imprescindível papel de professor, que esta pesquisa revela aparecer apenas em terceiro lugar, esteja fortemente presente, como condição para garantir a aprendizagem significativa dos alunos, sua motivação e envolvimento com o curso. Para tanto, as instituições possuem papel fundamental na organização do projeto do curso, na gestão e no processo de recrutamento e formação contínua 
dos professores tutores (Garcia; Silva, 2013).

\section{As múltiplas funções do professor tutor}

Discutiremos as respostas dos sujeitos em relação às funções que realizam como professores tutores organizando-as a partir das categorias apresentadas no Quadro 2 (pg.10). Os dados foram obtidos a partir da aplicação de uma escala do tipo Likert com 5 níveis (discordo totalmente, discordo, indiferente, concordo, concordo totalmente). Iniciamos com as funções relacionadas à Colaboração no Processo de Ensino-Aprendizagem. De maneira geral, os sujeitos demonstraram preocupação e empenho com o processo de aprendizagem dos alunos, afirmando desenvolver ações que visam promover reflexões para além dos materiais obrigatórios de leitura disponibilizados aos cursistas.

Grande parte (87\%) afirmou que participa ativamente das discussões nos fóruns e que propõe materiais adicionais para complementar a formação dos alunos. Interessante observar que $18,39 \%$ declararam não usar a sala de bate papo para retirar dúvidas e $24,61 \%$ são indiferentes a essa questão. Isso pode ser um indicativo de que há uma parcela que acredita não ser necessário utilizar ferramentas síncronas para discutir dúvidas com os alunos. Outro aspecto importante diz respeito a que $14,24 \%$ dos sujeitos afirmaram não promover conversas em particular com o aluno quando este manifesta interesse sobre um determinado conteúdo e 15,02\% são indiferentes a essa questão. Com esses dados, constatamos que, por um lado, há grande esforço da maioria dos professores tutores $(70,74 \%)$ na realização da mediação pedagógica, assumindo práticas comprometidas com o desenvolvimento cognitivo e profissional dos alunos, promovendo outros momentos e espaços capazes de colaborar ricamente com a aprendizagem. Por outro lado, verificamos que algumas ações relevantes não são, por vezes, realizadas, o que pode comprometer a qualidade da formação acadêmica.

Os sujeitos demonstraram grande preocupação com a dimensão da Motivação e Humanização. Suas respostas caminham com o disposto na literatura, que aponta ser necessário motivar o aluno ao longo do curso e que é preciso garantir que o ambiente virtual seja um espaço acolhedor, onde as relações são pautadas pelo respeito e colaboração. Afirmaram, em sua grande maioria (92\%), realizar intervenções quando um comportamento ruim de um aluno acontece para que logo seja retomado o clima agradável. Também relataram enviar e-mails ou realizar ligações para aqueles alunos que apresentam vontade de desistir do curso (82,3\%).

No entanto, quando indagados sobre a disponibilidade ao aluno, suas respostas revelam contradições. Embora um número considerável de sujeitos (38, 86\%) afirma 
ser muito difícil responder os e-mails aos alunos de forma rápida e estar sempre disponível para se comunicar com eles, grande parte (83,93\%) tem certeza que os alunos sempre sentem sua presença no ambiente virtual. Estar disponível para os alunos é relevante para o bom andamento de um curso online. Os alunos precisam sentir que seu professor tutor está "por perto", disponível para orientar, auxiliar nas dúvidas e discutir conteúdos. Acreditamos que o fato de $87 \%$ da amostra informar ter outro emprego, além do de professor tutor, colabora para a dificuldade desses sujeitos em criar "a sensação da presença síncrona" (Kenski, 2008, p.67) no ambiente virtual de aprendizagem.

A análise das respostas pertencentes à função de Avaliação confirmou o disposto na literatura. Gaytan e McEwen (2007) ressaltam a grande importância da avaliação para a garantia e sucesso da aprendizagem e sua complexidade de realização no campo relativamente novo da EaD. Boa parte dos sujeitos participantes da pesquisa informou que verifica constantemente o acesso dos alunos no ambiente virtual $(89,11 \%)$ e que sempre solicita aos estudantes avaliação sobre o andamento do curso e sugestões para melhorá-lo $(77,20 \%)$. Estes dados demonstram preocupação com a frequência do aluno e também com o andamento do curso, de maneira geral. No entanto, aos serem indagados sobre a avaliação das tarefas dos alunos, 31,34\% afirmaram não permitir que o aluno refaça uma atividade, oferecendo uma nova nota e $14,76 \%$ foram indiferentes a essa questão.

Sobre essa constatação, dois aspectos devem ser considerados. O primeiro, diz respeito à instituição que pode organizar o curso e a gestão de forma tradicional, despreocupada com o tempo de aprendizagem do aluno e com uma concepção de avaliação reduzida e centrada na classificação, o que dificulta ou mesmo impede que o professor tutor desenvolva uma avaliação formativa, contínua, centrada no aluno, com provocações e considerações que, devolvidas em forma de feedback, permitiria aos alunos reelaborar seus conhecimentos e refletir sobre suas concepções, crenças e práticas. O segundo aspecto se refere à própria concepção de avaliação pelo professor tutor. Se ele acredita ser tratar de um ato de verificar o que está certo e errado e atribuir uma nota final à tarefa do aluno, não terá a preocupação de realizar intervenções significativas, de ajudar a superar dificuldades, contribuindo, desta forma, para a manutenção de uma cultura avaliativa classificatória. Ainda, sua prática poderá servir como (mau) modelo para as ações avaliativas dos futuros professores (Gaytan; McEwen, 2007).

Contudo, ainda que existam concepções equivocadas, parte significativa dos participantes evidencia compreender o sentido da avaliação formativa. Sabemos que concepções e práticas possuem relação direta e, por esta razão, ressaltamos a importância da formação continuada desses profissionais, como possibilidade para ampliar e aprofundar seus saberes, com vistas a promover práticas emancipatórias de avaliação, comprometidas com o sucesso da aprendizagem dos alunos. 
A análise das respostas sobre as tarefas de Gestão/Administração revela que 68,3\% dos sujeitos concordam que a maioria das atividades elaboradas pelos professores autores das disciplinas é muito boa e aplicável com os alunos. Há, portanto, uma parcela considerável (31,7\%) que demonstra estar insatisfeita com as tarefas elaboradas pelos professores responsáveis pelas disciplinas, o que indica que esses professores tutores não concordam com a proposta de formação que recebem e a partir da qual precisam desenvolver suas práticas.

Quando questionados sobre a função de envolver os alunos no início do curso com o plano de ensino, diretrizes do curso e objetivos de aprendizagem, 86\% afirmaram que sempre desenvolvem essa ação por ser relevante para o bom andamento do curso. Entretanto, $48 \%$ afirmaram não conhecer o projeto político pedagógico do curso em que atuam. Esse dado é preocupante, pois aponta o pouco conhecimento e envolvimento dos professores tutores com os objetivos de aprendizagem e de formação dos estudantes.

É interessante observar que, ao serem indagados sobre a autossuficiência dos materiais instrucionais, 40,41\% acreditam que esses materiais são suficientes para promover uma excelente aprendizagem e $8,03 \%$ foram indiferentes a esta questão. Isso indica que estão presentes diferentes concepções sobre educação. Acreditar que os materiais instrucionais conseguem, sozinhos, dar conta de uma excelente aprendizagem significa retirar a grande importância do trabalho de mediação pedagógica que se espera e deseja ser realizado pelo próprio professor tutor no processo de colaboração de construção de aprendizagens dos alunos.

Sobre as funções referentes ao Crescimento Profissional, constatamos que, apesar da sobrecarga de trabalho, os sujeitos se esforçam para participar de atividades de formação oferecidas pelas instituições em que exercem suas funções (90\%) e também afirmam, largamente, buscar se atualizar sobre metodologias de ensino e aprendizagem online (93\%). Assim, é possível perceber a busca pela autoformação e o desejo de desenvolvimento profissional.

Os resultados sobre tarefas relacionadas à dimensão Técnica indicam que a grande maioria dos sujeitos $(84,72 \%)$ conhece as possibilidades e características de cada ferramenta do ambiente virtual. Assim, apenas 15,28\% declararam não ter esse conhecimento. Apesar de não se tratar de uma porcentagem alta, é preocupante, pois se trata do ambiente em que atuam e no qual necessitam conduzir o processo de ensino e aprendizagem. Desta forma, entendemos que o seu domínio é condição para o bom desenvolvimento desse processo.

Por último, os professores tutores também afirmaram que sempre oferecem feedback rápido aos alunos sobre dúvidas e problemas técnicos (92,48\%). Isso nos permite dizer que há a preocupação em garantir o bom funcionamento do ambiente e do uso de suas ferramentas para que os alunos possam desenvolver suas atividades. Interessante perceber que $54,92 \%$ declararam usar outros programas de edição de 
texto e criação de planilhas, além do ambiente virtual, para realizar seu trabalho. Assim, podemos deduzir que algumas funções e usos de tecnologias podem variar de instituição para instituição, demandando um número maior ou menor de tarefas e conhecimentos.

\section{Considerações finais}

Em um país continental como o Brasil, a educação a distância pode colaborar na tarefa de formar e emancipar sua população, historicamente excluída e marcada por profundas desigualdades sociais e pelo domínio de interesses privados (Costa e Pimentel, 2009). No entanto, para que esta formação seja de qualidade, comprometida com a ideia de educação como bem público, é preciso pensar formas de melhorar esse processo formativo e, sem dúvida, a melhoria da atuação e formação dos professores tutores significará uma grande contribuição para a melhoria da qualidade da formação de professores na modalidade a distância, pois a função tutorial se configura como um dos pilares sobre o qual se consolida a EaD (Padula, 2002). Para tanto, como enfatiza Garcia e Silva (2013), é necessário também cuidar do processo de recrutamento desses profissionais.

Os diferentes papéis e funções do professor tutor apresentados e discutidos neste trabalho revelam a complexidade da prática de formação de professores a distância. É preciso criar condições concretas para se efetivar mudanças no processo de formação na EaD e isto implica cuidar, sobretudo, dos formadores, pois de nada adiantará boa infraestrutura tecnológica se aqueles que desenvolvem a prática pedagógica não estão preparados para usá-la em prol da aprendizagem dos alunos.

A inquietação que ainda permanece e que é objeto de nossa preocupação é o papel de professor tutor na $\mathrm{EaD}$, o lugar a ele reservado para a intervenção pedagógica. Geralmente, não são os professores tutores que criam os materiais didáticos, mas são eles que discutem os conteúdos com os alunos, realizam a mediação e avaliam as tarefas. Assim, acreditamos que muito ainda precisa ser feito para que esses tutores se tornem, de fato, professores tutores, com papel e funções voltados para questões, decididamente, pedagógicas. Acreditamos que quando se perceberem, primeiramente, no papel de professor e quando forem formados para esta função, a educação a distância terá dado um salto qualitativo. E, não podemos nos esquecer de que as instituições de ensino superior têm papel fundamental nesse processo de qualificação do professor tutor. 


\section{Referências}

ALMEIDA, Maria Elisabeth Bianconcini. Educação a distância na internet: abordagens e contribuições dos ambientes digitais de aprendizagem. Educação e Pesquisa, São Paulo, v. 29 n. 2, jul/dez, 2003. Disponível em: <http://www.scielo. $\mathrm{br} /$ scielo.php?pid=S1517-97022003000200010\&script=sci_arttext>. Acesso em: 03/10/ 2009.

ALONSO, Myrtes; ALEGRETTI, Sonia. Maria. Introduzindo a pesquisa na formação de professor a distância. In: ALMEIDA, Maria Elisabeth. Bianconcini et al. (Org.). Educação a distância via internet. São Paulo: Avercamp, 2003.

BELLONI, Maria. Luiza. Educação a distância. Campinas: Autores Associados, 2009.

BERGE, Zane; COLLINS, Mauri. Perceptions of e-moderators about their roles and functions in moderating electronic mailing lists. Distance Education, p. 81-10, 2000. Disponível em: < http://www.tandfonline.com/doi/ abs/10.1080/0158791000210106l>. Acesso em: junho de 2015.

BERROCOSO, Jesús Valverde; GARRIDO ARROYO, María del Carmen. La función tutorial en entornos virtuales de aprendizaje: comunicación y comunidad. Revista Latinoamericana de Tecnología Educativa. v. 4, n. 1. 2005. Disponível em: <http:// www.unex.es/didactica/relatec/csumario_4_1.htm >. Acesso em: 08/01/2016.

BRASIL. Lei N. 9.394, de 20 de dezembro de 1996. Estabelece as Diretrizes e Bases da Educação Nacional. Diário Oficial da União. Brasília. 23 de dezembro de 1996.

BRASIL. Ministério da Educação. Projeto de Lei do Plano Nacional de Educação para o decênio 2011-2020. Disponível em: <http://portal.mec.gov.br/index. php?option $=$ com $\_$content $\& i d=16478$ \&ltemid $=1107>$. Acesso em: $10 / 01 / 2014$.

CASTELLS, Manuel. O poder da identidade. Vol. II. Rio de Janeiro: Paz e Terra, 2002.

CHANEY, Elisabeth et al.. Development of an instrument to assess student opinions of the quality of distance education courses. The American Journal of Distance Education, p. 145-164. sep. 2007.

CORDEIRO, Jaime. A relação pedagógica. In: UNIVERSIDADE ESTADUAL PAULISTA. Prograd. Caderno de Formação: formação de professores didática geral. São Paulo: Cultura Acadêmica, 2011, v. 9, p. 66-79.COSTA, Celso José; 
PIMENTEL, Nara Maria. O sistema universidade aberta do Brasil na consolidação da oferta de cursos superiores a distância no Brasil. ETD - Educação Temática Digital. Campinas, v.10, n.2, p.71-90, jun. 2009. Disponível em: < http://www.fae. unicamp.br/revista/index.php/etd/article/view/2030>. Acesso em: 12/02/2016.

DOURADO, Luiz Fernando. Políticas e gestão da educação superior a distância: novos marcos regulatórios. Educação e Sociedade. Campinas, vol. 29, n. 104 Especial, p. 891-917, out. 2008.

EMERENCIANO, Maria do Socorro; SOUSA, Carlos Alberto Lopes, FREITAS, Lêda Gongalves. Ser Presença como Educador, Professor e Tutor. Colabor@ - Revista Digital da CVA. V. 1, N. 1, p. 4-11, Ago/ 2001.

FERREIRA, Zeila Miranda; GARRIDO, Elsa. Caminhos e descaminhos do tutor na formação Superior de professores dos anos iniciais do Ensino fundamental, 2005. Disponível em: <http://www.abed.org.br/congresso2005/por/pdf/021tcf5.pdf>. Acesso em: 06/04/2012.

FERREIRA, Aurélio B. de Holanda. Dicionário Aurélio da Língua Portuguesa, 2010.

FREITAS, Helena Costa Lopes. A (nova) política de formação de professores: a prioridade postergada. Educação e Sociedade. Campinas, vol. 28, n. 100 - Especial, p. 1203-1230, out. 2007. Disponível em: <http://www.cedes.unicamp.br>. Acesso em: 07/02/2012.

GARCIA, Dirce Maria Falcone. Educação a distância, competências, tecnologias e o trabalho docente: pontuando relações, fragilidades e contradições. In: In: GARCIA, Dirce Maria Falcone; CECíLIO, Sálua. (Org.). Formação e Profissão docente em tempos digitais. Campinas: Alínea, p. 217-235. 2009.

GARCIA, Marta Fernandes; SILVA, Dirceu. Concepções dos tutores do programa Unesp/Univesp sobre formação a distância. Linhas Críticas, Brasília, DF, v.19, n.40, p. 579-593, set./dez. 2013.

GARCÍA ARETIO, Lorenzo. La educación a distancia. Una visión global. Boletín Llustre Colegio de Doctores y licenciados de España, p. 1-22. 2003. Disponível em: < http://www.uned.es/catedraunesco-ead/articulos/2003/la\%20educacion\%20 a\%20 dista ncia\%20una\%20vision\%20 global.pdf >. Acesso em: 12/12/2011.

GATTI, Bernadete. Formação continuada de professores: a questão psicossocial. Cadernos de Pesquisa, São Paulo, n. 119, p. 191-204, jul/2003.

GAYTAN, Jorge; MCEWEN, Beryl. Effective online instructional and assessment strategies. The American Journal of Distance Education, p. 117-132. 2007. 
HOUAISS, A. Dicionário Eletrônico Houaiss da Língua Portuguesa. 2008.

NACIONAL DE ESTUDOS E PESQUISAS EDUCACIONAIS ANÍSIO TEIXEIRA. Sinopse Estatística da Educação Superior 2015. Brasília: Inep, 2016. Disponível em: $<$ http://portal.inep.gov.br/basica-censo-escolar-sinopse-sinopse>. Acesso em: 11/10/2016.

KENSKI, Vani Moreira. Tecnologias e ensino presencial e a distância. São Paulo: Papirus, 2008.

LAPA, Andrea; PRETTO, Nelson de Luca. Educação a distância e precarização do trabalho docente. Em Aberto, Brasília, v. 23, n. 84, p. 79-97, Nov. 2010.

LEAL, R. B. A importância do tutor no processo de aprendizagem a distância. Revista Iberoamericana de Educación, p. 1-6. 2004.

LÉVY, P. Cibercultura. São Paulo: Ed. 34, 2000.

MAGGIO, M. O tutor na educação a distância. In: LITWIN, Edith. (org.). Educação a Distância. Porto Alegre: Artmed, p. 93-110, 2001.

MASETTO, Marcos Tarciso. Mediação pedagógica e o uso da tecnologia. In: MASETTO, Marcos Tarciso et al. Novas tecnologias e mediação pedagógica. Campinas: Papirus, 2009.

MAURI, Teresa; ONRUBIA, Javier. O professor em ambientes virtuais: perfil, condições e competências. In: COLL, César; MONEREO, Carles. (Org.). Psicologia da educação virtual: aprender e ensinar com as tecnologias da informação e comunicação. Porto Alegre: Artmed, 2010. p. 118-135.

MOORE, Michael; KEARSLEY, Greg. Educação a distância: uma visão integrada. São Paulo: Cengage Learning, 2008.

MOULIN, Nelly; PEREIRA, Vilma; TRARBACH, Maria Aparecida. Formação do tutor para as funções de acompanhamento e avaliação da aprendizagem à distância. Disponível em: < http:/ /www.abed.org.br/congresso2004/por/htm/018-TC-A2. htm>. Acesso em: 27/01/2014.

PADULA, Jorge. Contigo en la distância: el rol del tutor en la educación no presencial, 2002. Disponível em: <http://www.uned.es/catedraunescoead/ publicued/pbc08/rol_bened.htm>. Acesso em: 09/01/2014. 
PALLOFF, Rena; PRATT, Keith. Construindo comunidades de aprendizagem no ciberespaço: estratégias eficientes para salas de aula on-line. Porto Alegre: Artmed, 2002.

PALLOFF, Rena; PRATT, Keith. O aluno virtual: um guia para trabalhar com estudantes on-line. Porto Alegre: Artmed, 2004.

PIMENTA, Selma. Garrido; ANASTASIOU, L. G. C. Docência no ensino superior. São Paulo: Cortez, 2010.

PRADO, Maria Elisabette Brisola Brito; ALMEIDA, Maria Elisabeth Bianconcini. Redesenhando estratégias na própria ação: formação do professor a distância em ambiente virtual. In: ALMEIDA, Maria Elisabeth Bianconcini de et al. (Org.). Educação a distância via internet. São Paulo: Avercamp, 2003.

PRETI, Oreste. O estado da arte sobre "tutoria": modelos e teorias em construção. Capítulo 1 do Relatório de Pesquisa "O sistema de Orientação Acadêmica no curso de Pedagogia a distância da Universidade Federal de Mato Grosso". Programa CAERENAD, 2003.

SILVA, João Augusto Ramos et al. Avaliação de Tutores: elaboração de um instrumento, 2009. Disponível em: < http://www.abed.org.br/ congresso2008/ tc/51120 08104452PM .pdf>. Acesso em: 12/02/2016.

TEZANOS, José Félix. Desigualdad y exclusión social en las sociedades tecnológicas. Revista del Ministerio de Trabajo y Asuntos Sociales, p. 35-53, 2011.

Recebido em agosto de 2016

Aprovado em junho de 2017

Marta Fernandes Garcia é Professora do Instituto Federal de São Paulo, campus Cubatão. Doutoranda em Educação pela Universidade Estadual de Campinas/ UNICAMP. Pesquisadora do Grupo de Estudos e Pesquisas em Educação Superior GEPES/UNICAMP. Email: marta_fgarcia@yahoo.com.br

Dirceu da Silva é Doutor em Educação pela USP. Professor da Faculdade de Educação da UNICAMP. Email: dirceu@unicamp.br 